\title{
Assessing, Deliberating, Responding: An Annotated Bibliography for a Post-Truth Age
}

\author{
Jacob D. Richter* \\ $10 / 1 / 2020^{\dagger}$
}

\begin{abstract}
The Infosphere Probe is a project geared toward re-envisioning some features of traditional annotated bibliography assignments in an attempt to empower contemporary information citizens. By challenging students to assess the information circulating in their everyday lives, the Infosphere Probe explores strategies with which contemporary classrooms might nurture and cultivate empowered information practices that appreciate lived information cultures traditionally neglected within academic discourse.
\end{abstract}

\section{Introduction: Lived Information Cultures}

College writers compose in crisis. A multitude of crises might qualify as referents for this statement, but it is the crisis affecting contemporary students commonly labelled post-truth that has most-recently captured the attention of many within higher education (Carillo, 2018; Peters, 2017). Bruce McComiskey (2017) cites the Oxford Dictionaries' definition of post-truth, referring to an information landscape in which "objective facts are less influential in shaping public opinion than appeals to emotion and personal belief" (p. 5). Suffice it to say, contemporary students write and compose both informally and academically each day within complex rhetorical situations that are characterized by highly hybridized forms of media, complicated information streams, and competing rhetorical exigences. In an age of constant uncertainty surrounding the validity and motives of circulating information, the ability to discern and assess the value of that information is more complicated than ever.

This essay explores the complicated rhetorical situations modern students confront, arguing that a targeted, revitalized version of an annotated bibliography assignment in college

\footnotetext{
${ }^{*}$ Clemson University, jdrich@g.clemson.edu. Copyright 2020 Jacob D. Richter. This work is licensed under a Creative Commons Attribution-Noncommercial. International License (http://creativecommons.org/licenses/by-nc/"./).

${ }^{\dagger}$ Submitted, 2/22/19; Accepted, 5/11/20.
} 
classrooms is capable of nurturing versatile, dynamic practices as students assess, deliberate, and respond to increasingly complex information ecologies. The assignment outlined here acts on the belief that the information students happen upon in their everyday lives - the Tumblr fandoms they are a part of, the video gaming Twitch streams they subscribe to, the 2 Dope Queens podcast they listen to on the bus that brings them to class - function as sites of identity, culture, and literacy formation, and as such are just as integral to the work of the university classroom as more established "academic" information practices.

Approaches for mobilizing students' "extra-curricular" or "extra-academic" literacies have been outlined by a diverse array of writers in higher education, including Chiseri-Strater (1991), Gere (1994), and Roozen (2008). So far, however, the relationships between these extra-curricular literacies and the annotated bibliography assignments commonly assigned in many classrooms have remained comparatively underexplored. This essay strives to rally these at-home literacies as meaningful sites of cultural knowledge. When foregrounded in a revised annotated bibliography assignment, these literacies may prove capable of nurturing practices that connect information literacy with the possibility of dissolving, at least partially, the fictitious divide between "academic" literacies and the various lived cultural literacies students bring to the classroom. These literacies that students contribute, what I call lived information cultures, can be foregrounded in college classrooms in ways that respond to complex information ecologies strategically and tactically for the benefit of our classrooms and our students. Initiatives that challenge students to "read against the grain" are already a well-established practice in post-colonial and critical race studies and pedagogies (Hartman, 2007; Lowe, 2015; Smallwood, 2007). This project attempts to extend these critical reading practices to a large array of documents, texts, media, and phenomena that influence students' lives. If we devise ways to foreground these lived information cultures, we might also find ways to realize students' traditionally-excluded lived literacies as visible, valuable sites for literacy education.

This essay does not attempt to solve or to address the complex, multifaceted problems contained in the term post-truth, but it does propose a new method to cultivate important skills of information literacy that more accurately explore students' lived information cultures. In an age dominated by social media, smartphones, and ubiquitous computing in which the term writer is nearly synonymous with the term digital writer, the stakes for higher education are quite clear: the relationship central to education that is formed between students and the information they encounter is rapidly transforming. Such a situation complicates the rhetorical situations that students face and conduct academic work in, and inspires the question of what forms of writing and academic assignments might nurture responsible, empowered information practices within an age of perpetual information uncertainty. ${ }^{1}$

An assignment that could help empower students' informational literacy skills is an annotated bibliography assignment called the Infosphere Probe that asks students to reflect on their 
Richter "Assessing, Deliberating, Responding"

habitual, everyday practices and relationships with the information they consume. This assignment invites students to explore how their own beliefs, emotions, and approaches to the world come to be informed by their relationships with the information they encounter. The assignment then mobilizes these reflections toward a clear goal: to probe practices of modern information consumption, and then to assess, deliberate, and help students to respond productively with lived information cultures in mind.

\section{Project: The Infosphere Probe}

The Infosphere Probe asks students to survey and collect examples of discourse surrounding a social, cultural, or political issue from streams of information traditionally not foregrounded within academic discourse, in addition to several more traditional genres of academic analysis: a peer-reviewed academic journal article, but also two Tweets or similar social media posts, a popular news article from a newspaper or web-based news site, an opinion piece from a newspaper or online news source that makes an argument concerning the topic at hand, and a news program or television talk show video segment (likely found on YouTube). Finally, students are challenged to additionally assemble four streams of information the assignment has not yet formally called for of the student's own original choosing.

This final component represents the core raison-d'être of the assignment design. The assignment encourages students to take risks here, to find original information streams that the assignment does not formally codify. Some students mobilized verbal streams of information into their Infosphere Probe, noting and transcribing summaries of conversations they had had on the phone with their parents or heard in conversation on the public transit system that morning. One student found a Tweet that led her to a blog documenting the dangers of an anti-vaccination campaign, while another student was led to the Instagram account of a well-known journalist associated with the \#MeToo movement, allowing her to mobilize the entire Instagram account as a site of analysis rather than just one specific post. Students also collected and explored information streams that were entirely off the beaten path-including the probing of podcasts, internet memes, commercials, advertisements, graffiti, Twitch video game streams, political cartoons, songs, poems, stories, smartphone applications, TikTok videos, articles from The Onion, bumper stickers, junk mail content sent to email accounts, conversations overheard at the library, interviews with parents and family members, even flyers found in mailboxes - all of which are impactful and valuable components of various infospheres.

Along the way, students discover how worldviews, attitudes, perspectives, and identities are formed through media streams that are directly investigated only infrequently in the college classroom. The Infosphere Probe challenges students to examine both mass information streams they encounter regularly (mass-market films, morning radio, paperback books, 
newspaper articles) and more specialized information streams introduced to them within this project (such as public radio stations like $N P R$, podcasts such as 2 Dope Queens and Modern Love, Instagram posts from amateurs and from corporate entities, even hashtags found on Twitter arising out of a grassroots political protest contrasted to those promoted in a television commercial). The reflective aspects of this assignment are crucial. We are careful to discuss the information streams present in students' everyday lives: how they consume news, whether it be on television or through social media; how they hear about issues of national prominence, and how they do or do not discuss these issues; how they might possibly respond to public policy debates, whether in writing or in another form.

I chose to name the assignment the Infosphere Probe for two reasons. First, the word infosphere was deliberately chosen for its active, unfixed, and energetic connotations, and also for its overtones of distributed, collaborative, and ecological approaches to discourse production championed by composition theorists such as Karen Burke LeFevre (1986) and Jenny Edbauer (2005). The word infosphere contains denotative definitions of "the movement of information," in a "dynamic environment" of complex actors "concerned with the collection and processing of information," according to the Oxford English Living Dictionary. By examining a variety of layers within the chosen issue's accompanying infosphere, students translate old knowledge of media forms into new, constructed knowledge of motive, currency, value, and bias, all the while mobilizing existing literacy skills into a complex, layered exploration of the many forms of information vital to our conceptions of lived information cultures. Secondly, the word probe is meant to elicit an understanding of the assignment as an exploration, as an exercise of discovery, as an expedition into the unknown. It is a word choice intended to invoke attitudes of discovery, attitudes in which it is okay to step out into something new, to take risks. ${ }^{2}$

\section{Praxis: Assessing, Deliberating, Responding}

Annotated bibliographies are by no means a homogeneous genre of assignments, but they generally tend to entail similar practices and learning outcomes. In general, these assignments tend to value documents, texts, and discourses perceived as "academic" more highly than those deemed "popular" or "unscholarly." Painting with a broad brush, I observe that annotated bibliography assignments oftentimes attempt to jump-start the research process in preparation for a larger assignment or project, as a number of popular composition textbooks at least partially endorse (see Alfano \& O'Brien, 2016; Clark, 2016). Annotated bibliography assignments exist in a broad array of forms, variations, and instantiations, and rather than cement a static, single, "traditional" interpretation of what an annotated bibliography is, this essay deliberately uses the term "established" to characterize annotated bibliography assignments that, while at times privileging texts that embody power and privilege, have also contributed valuable knowledge and learning to college classrooms. "Established" annotated bibliography assignments are not homogeneous, 
uniform, or unvarying, and help nurture a number of valuable skills for college learners, but in general they do tend to work toward goals and outcomes differing from those foregrounded in the Infosphere Probe.

Established annotated bibliography assignments do not always emphasize the whole of an infosphere, the many popular dimensions that are frequently at the forefront of a student's information-consumption lives. For example, an "established" version of an annotated bibliography assignment primarily valuing academic books and research articles might not readily challenge a student to locate and survey the Tweets surrounding the 2018 murder of Washington Post journalist Jamal Khashoggi, or to compare the reaction to Khashoggi's murder on vlogs to those on corporate-managed YouTube media accounts, or to critique the coverage of the event by television and in internet spaces from major media outlets compared to the reception from general news podcasts such as The Daily and more specialized podcasts like Pod Save the People. Similarly, these assignments oftentimes ignore what a student might hear on the "street" from their parents, friends, and professors; what students might overhear in the fast-food line or on the campus bus; or what that student might be exposed to in one manner in high school but quite differently in collegiate settings.

After teaching an "established" version of an annotated bibliography assignment for a number of semesters, I began to consider the literacies that tend to be nurtured by these annotated bibliography designs (academic and scholarly, generally focusing on university databases and academic journals, with occasional "popular" sources such as web articles and magazine stories spliced in) and the literacies they tended to focus on less frequently (those literacies that students rally in most other facets of their lives). The Infosphere Probe emerged as I resolved to design an occasion for my students, distinct from established annotated bibliography assignment designs, in which students might productively explore and discover within the information spheres so integral to their information lives. I began to question what we as instructors were nurturing, asking students to only research in "academic" spaces such as university databases for content that is unfamiliar to them. Would it not be equally beneficial, I began to believe, to have students mine what is familiar to them? Would it not be beneficial to ask students to reflect on and explore their actual lived information cultures, in all of their diversity and difference, rather than teach only sanitized, homogenized, and monolithic approaches to what types of information are valued in the classroom? This approach would, at minimum, empower and make visible the cultural and personal literacies students are typically taught to stow away upon entering conventional college classrooms. ${ }^{3}$

Many established approaches to the annotated bibliography do not prioritize research practices that encompass all aspects of a contemporary infosphere, including all of its digital components and the lived information cultures of students, researchers, and writers. When we privilege an emphasis on locating and articulating the merits of only academic 
resources, and forgo extending research into an entire infosphere, we privilege content that is narrowly-defined, content that diverges greatly from students' lived information cultures, and content that represents only a small facet of the texts that might inform students' forays into the conversations of their culture. These privileged texts often uphold structural hierarchies along lines of race, gender, class, and ability, and can implicitly deny students the ability to bring the narratives and counternarratives important to them into the classroom as sources of information that impact their unique lived information lives. While ignoring academic texts entirely would do a disservice to students by limiting access to valuable existing scholarship that might help them to survey a cultural conversation or a lived information culture, exploring both conventionally-neglected information sources in addition to more conventional academic texts ensures students probe as much of an infosphere as possible. In this way, students examine the diverse array of texts to be found in a particular cultural conversation's infosphere without ignoring the insights of valuable academic research. Among the goals of the Infosphere Probe is to immerse students within a plurality of texts from a variety of different authorial backgrounds and with a variety of different purposes, motives, exigencies, styles, and modes of expression. The goal is to pluralize what counts as a meaningful academic resource without excluding conventional academic resources, which still remain quite valuable within the Infosphere Probe.

A re-thought annotated bibliography assignment might be wise to mobilize the narratives and counternarratives that help constitute students' lived information cultures, consciously framing them as assets to the classroom community in all of their plurality, their diversity, and their valued difference. By consciously reflecting on how diverse information cultures create a classroom environment in which we can learn from one another and appreciate the generative possibilities of our differences, we are able to partially realize the benefits of a manifold, deliberately heterogeneous approach to literate action in our classrooms, as championed by theorists such as Elaine Richardson (2003), Vershawn Ashanti Young (2010), and Barrett et al. (2018). Following this, the Infosphere Probe represents one possible classroom initiative in which the historically-excluded literacies that students of color and students from underrepresented groups bring can be not just discussed, but rather foregrounded, made visible, and celebrated for their rich contributions to our classroom literacy education.

An approach to the annotated bibliography assignment that visibly foregrounds information plurality might challenge students to explore, to survey, and to assess and deliberate upon as many different, multifaceted information streams and media forms as possible. Asking a student to assess the currency, authority, relevance, reliability, purpose, motives, circulation, and overall value of "academic" resources is crucial and paramount to cultivating empowered information citizens, but teaching them to assess and deliberate on all forms of rhetorical communications they encounter in contemporary infospheres assures students are taking steps toward framing information literacy as an approach for use both inside and outside of the college classroom. This approach to the annotated biobibliography 
assignment and to framing lived information cultures is by no means the only method educators might employ toward furthering the goals outlined here, but this approach does present one tangible strategy for mobilizing extra-curricular literacies in a college-level assignment. Groundbreaking and impactful work on reading archives and information sources "against the grain" has been extensively articulated in disciplines such as critical race studies (see Hartman, 2007; and Smallwood, 2007) and postcolonial historiography (see Lowe, 2015), presenting valuable exigences for students to assess, deliberate, and respond productively to information they encounter through academic assignments such as the annotated bibliography.

The Infosphere Probe draws upon these valuable critical reading strategies and mobilizes similar practices of thoughtful, strategic interpretation by challenging students to ask which groups of people author, benefit from, and work to amplify or extend the reach of particular information sources. In this way, the Infosphere Probe assignment extends previous critical reading research to probe infospheres against the grain, broadening the ways students approach power, privilege, and the interpretation of information. Challenging students to read information and infospheres in tactful ways is not unique to this assignment, but the framing, goals, and outcomes in this particular case are strategically designed to expand students' conceptions of how to engage productively with texts, information ecologies, and cultural artifacts, as well to nurture the capacities of students to assess, deliberate on, and respond to infospheres of importance. The response outlined here is by no means the only way instructors and teacher-scholars have responded to contemporary information exigences, but nonetheless, the approach may be of use to instructors wishing to pluralize and diversify the texts their students engage with, critique, and use to inform themselves within a particular course setup or curriculum.

\section{Method: Designing Occasions for Inquiry}

I most recently taught this iteration of the Infosphere Probe during the Spring semester of 2020 in a first-year composition (FYC) course. As this was a general education course, a diverse spectrum of majors was represented spanning the humanities, STEM, and other fields and disciplines. This particular course functioned as a broad introduction to rhetoric, composition, and academic genres, and oftentimes challenged students to engage with social and cultural issues through research and argument practices. Although the Infosphere Probe was generally considered a stand-alone assignment, the practices in researching, analysis, and information appraisal were continually drawn on in subsequent assignments, including in researched argument-driven and multimodal composition projects that followed completion of the Infosphere Probe in the course. Both of these subsequent projects drew upon the skills of research, analysis, and creative engagement with cultural artifacts that the Infosphere Probe nurtures. In other words, students seemed to benefit in the remaining arc of the course from the in-depth engagement with both familiar and unfamiliar cultures, 
literacies, and points of view necessitated by the Infosphere Probe. For instance, the course's final project challenged students to create a multimodal text examining our university's histories with structural racism, slavery, and race-based exploitation, and the Infosphere Probe's deep engagement with critical analysis of a wide variety of information sources helped prepare students for research in our university archives, which contain information in a variety of forms.

Upon beginning the project, I first showed students sample projects voluntarily shared by students from previous iterations of the course to give them an idea of how they might engage the goals of the assignment in their own way. I then provided students free time to explore topics that might be of interest to them from two similar websites, ProCon.org and Kialo.com. These sites perform similar functions for students, as they outline the parameters of a cultural conversation, sketching and depicting various key figures, events, or points of contention within that conversation. For instance, one student explored ProCon and found an article surveying the cultural conversation surrounding standardized testing in American high schools, a topic of which she had first-hand experience and knowledge. Other students approached these websites more heuristically, using them to visualize what cultural conversations might look like and innovating from there based on their own experiences or interests. An important aspect of this project is that students select a topic that furthers the goals of the assignment, but that also engages their own interests, experiences, or histories, including topics that facilitate exploration of their individual lived information cultures.

The array of student writing resulting from this assignment was diverse, and facilitated not only valuable conversations surrounding information and literacy, but also furthered discussions of lived information cultures as we moved throughout the full arc of the course. One student, an engineering major, traced public discussion of recent Boeing plane crashes across academic journal articles, YouTube conspiracy videos, a political cartoon, even technical documents showcasing the layouts of the planes released by Boeing itself. Another student who studied environmental science probed the impact of feral pigs on local ecosystems, interviewing her grandfather and a local farmer for their opinions, as well as assembling a local DEC document, a bumper sticker, a television program, and even a viral meme to explore the issue.

After researching, exploring, and assembling their information sources, students then cite each source using proper MLA documentation and compose a paragraph of analysis for each source. After students assemble their various streams of information, the Infosphere Probe challenges them to probe and explore questions related to the source's credibility, intended audience, purpose, motive, and information type (i.e. do students think the information is opinion, speculation, scientific, descriptive, narrative, or something else?). This sort of analysis does not diverge heavily from other forms of annotated bibliography assignments. However, the Infosphere Probe then challenges students to probe each information source for other questions that engage the larger goals of the assignment, including how the medium 
Richter "Assessing, Deliberating, Responding"

of delivery impacts the contained information, how each source represents particular groups of people, and who students think might agree or disagree with the information each source contains. Lastly, students are asked to reflect on how that source represents someone's lived information culture, including their own.

Some students struggled initially to come to terms with the goals, purpose, and intended learning outcomes of the assignment, but after beginning the process of researching, most seemed to embrace the opportunity to "dig deep" and explore their everyday information lives and information diversities. For example, one student who otherwise only infrequently participated vocally in course discussions ended up being one of the more expressive participants throughout the arc of this project because it allowed her to engage her firm opposition to the building of a wall on the U.S.-Mexico border. Additionally, another student clearly found the project intellectually invigorating, narrowing his topic from smartphones to artificial intelligence and finally to digital surveillance based upon the assembled research items he found. The project's ultimate goals of discovery, exploration, creative inquiry, and critical reflection were pushed and expanded continually, with students navigating real-world, public rhetorical ecologies and discourse communities and then probing, sorting, and responding to the information they had investigated. These goals helped prepare students not only for the research-intensive argumentative and multimodal projects that followed the Infosphere Probe, but also for the critical reflection, creative capacities, and understanding of diverse literacies that the remainder of the course continued to engage.

Upon completing the primary components of the project, students are then challenged to assemble a short Infosphere Analysis, a summary exercise which reflects on and outlines the probing and exploring the student has processed and uncovered. The Infosphere Analysis is a short document (2 paragraphs or so) intended to chronicle, compare, contrast, and synthesize the different components of the infosphere the student's investigation has uncovered. Importantly, the Infosphere Analysis is not an attempt to reconcile incompatible, conflicting, or clashing content discovered in differing streams of information. Rather, it works as an attempt to cultivate approaches to information valuing and appraisal that are flexible, culturally empowered, and that appreciates the value heterogeneous arrays of information streams can provide.

\section{Conclusions: Probing Broadly Across Disciplines}

The framing outlined here is one of many possible approaches attempting to mobilize extra-curricular literacies and "against the grain" reading practices to more fully respond to complex information landscapes, and a variety of applications in other disciplines and courses might approach the Infosphere Probe in fresh, innovative ways. For example, in an engineering course, a variation of the Infosphere Probe project outlined here might ask students to trace cultural conversations surrounding autonomous vehicles or hardware 
advances in quantum computing in an effort to extend student inquiry, reflection, and problem assessment, and to broaden students' understandings of possible outcomes and ramifications resulting from particular engineering decisions. Similarly, in a science course, this sort of initiative might challenge students to explore climate change discourse within their own lived information cultures, extending course content and conversation into the constellation of circulating media discourses so integral to the formulation of the climate crisis. If we as educators are to foster environments of inquiry, exploration, and informed information practices, we would benefit from designing occasions for our students in which they are free to explore an issue within their culture as it is developed in-process and in-motion by a variety of interested voices.

\section{Assignment: The Infosphere Probe}

(To view a PDF facsimile of the original formatting of this assignment, return to this article's homepage and locate the link to the "Assignment" PDF.)

\section{Assigned: Wk. 5 Due: Wk. 9}

Think about it. Information is all around you, surrounding you, circulating on your phone, your computer, in your mind. Information permeates every experience you have. Information arrives to you from the evening news, from calls home to your family, from your social media feeds, from the signs you see on the street and on TV. The information you encounter helps to expose you to new ideas or to repeat old ones. This information might try to sell you on some product; it may present an event in a particular frame or lens or narrative; it may try to persuade you to believe in a particular point of view; it might even attempt to mislead you or to deceive you in some way. Undoubtedly, though, the information a person encounters helps to determine that person's opinions on social, cultural and political issues that have real-life impacts on the world we all contribute to. The information a person is exposed to, then, goes a long way toward influencing that person's approach to their world and to particular issues, and helps to form a lived information culture that person might develop.

This assignment challenges you to probe these ideas by investigating an infosphere to assess a conversation happening in our culture surrounding some issue of social, political or wider cultural importance. An infosphere is a conversation surrounding a particular topic that occurs on Twitter, on the evening news, in conversations on the street, in coffeeshops, in all realms in which people communicate with one another, both online and off. An infosphere is made up of Tumblr fandom blogs, of Twitch video game streams, of podcasts like 2 Dope Queens or Crime Junkie that you listen to on the bus on your way to class. The conversation you investigate may take on a variety of forms, but a good place to start might 
be in venturing a possible answer to the question: What is the most important social or cultural issue currently impacting your life?

To assess a conversation from a variety of information streams that we as information citizens encounter on a daily basis, you will survey and assess: (A) A peer-reviewed academic journal article that relates to your cultural issue; (B) A popular news article from a newspaper or web-based news site, national or local; (C) An opinion article published online that make an argument regarding your topic (D) Two Tweets, blog posts, or similar social media posts, (E) A news program or television talk show segment (likely found on YouTube), and (F) Four streams of information this assignment hasn't yet formally called for of your own original choosing (students in the past have found podcasts, internet memes, commercials, advertisements, graffiti, Twitch streams, political cartoons, songs, poems, stories, smartphone applications, TikTok videos, articles from The Onion and other satire news sites, bumper stickers, junkmail content sent to email accounts, conversations overheard at the library, flyers found in mailboxes, etc.). Be creative and push boundaries. Bonus points if you ask a parent, a guardian, a friend, or a professor for their perspectives on your issue, or if you overhear something on the bus, in the fast-food line, or in the hallway. A major point of priority with this project is the realization that streams of information turn up in every facet of our lives, even in places we'd normally not consider worthy of academic attention and scrutiny. These everyday information streams, ultimately, help to make us who we are, and inform our knowledge of the people, cultures, and communities of the world. Part of this assignment asks you to draw on your own personal background, history, heritage, or story to probe how the information found in your life has impacted your identity, your outlook, and your view of the world.

When you've located the above materials, cite them using proper MLA format (see Purdue OWL resources), and then write a short paragraph for each source type or component letter (ex. write a single paragraph for the two Tweets/social media posts you've found, not a paragraph for each Tweet, though you will write an individual paragraph for each of your four unique materials; you'll have 9 paragraphs total, plus your 2-paragraph Infosphere Analysis). Each Infosphere Probe paragraph will probe and explore any or all of the following questions: What types of information is contained here-opinion, speculation, factual, scientific, descriptive, narrative, etc.? What is the purpose or motive of the source? What is its currency, authority, relevancy, or circulation? Who is its audience? Who might agree/disagree/respond? How does the particular medium of information delivery impact the content of the source? How does the source represent someone's lived information culture? How are particular groups, peoples, or communities represented, articulated, empowered, or made visible by the source? Your contribution will be assessed based upon the level of detail within your analysis as well as the engagement with the learning objectives of the assignment that you display. 
When you've completed the 9 paragraphs that form your Infosphere Probe, close this project by assembling a 2-paragraph Infosphere Analysis in which you explain to your reader what your probe uncovered: What did you find? What are people in the infosphere saying about your cultural issue? How do people connect in their opinions? How do they diverge? How are the texts you've assembled intertextual? How do they interact with one another? Did you find moments of consensus, conflict, synthesis? What struck you or surprised you? How do the differences between stakeholders in your infosphere inform popular culture, public sentiment, or political happenings? The goal of this Infosphere Analysis is not to reconcile, summarize, or condense conflicting or clashing information found in your infosphere exploration, but rather should be an attempt to explain the value that flexible, culturally-empowered, and diverse arrays of information streams can provide to understanding cultural issues.

\section{Notes}

\footnotetext{
${ }^{1}$ Fortunately, the phenomena of post-truth have not occurred without a variety of both academic and popular responses. In the field of library and information sciences, Mary K. Oberlies and Janna Mattson's Framing Information Literacy (2018) features a number of essays useful to instructors attempting to mobilize multifaceted, rounded digital literacy strategies in their students through active learning assignments and activities. Similarly, Mary Snyder Broussard's book Reading, Research, and Writing (2017) ventures to connect information literacy with the processes of reading, researching and responding so crucial to writers in post-truth environments. Additionally, the anthology Alternative Facts, Post-Truth and the Information War (2018) collects pieces from various popular news sources that outline the post-truth phenomenon and explore some of its specific manifestations, many of which instructors might draw on to illustrate post-truth for their students.

${ }^{2} \mathrm{~A}$ student does not need to have an in-depth knowledge of the ins-and-outs of Twitter to probe the conversation happening there surrounding the \#BlackLivesMatter hashtag. Additionally, much new knowledge can be stumbled upon in the exploratory research process the Infosphere Probe encourages, such as a student discovering podcasts such as Broken English and Status that provide first-hand stories and perspectives from immigrants to the U.S. One change I hope to employ in future iterations of this assignment is to encourage students to more visibly acknowledge the intended audience for a particular text or artifact, and to challenge students to speculate as to how that text caters to a particular group of people. I envision a comparative element to this initiative in which students compare and contrast how different texts serve different ends, including for privileged and marginalized groups.

${ }^{3}$ The classroom should be a place in which student plurality, diversity, and difference are valued and celebrated. In the annotated bibliography assignments I had been teaching, the frame of mind we cultivated implicitly conveyed to students that informational materials they find inside of the formal confines of the college classroom bear little resemblance to the opinions, expressions, and rhetorical appeals they encounter on their smartphone's Twitter and Instagram applications, on the advertisements streamed on services such as Hulu or Netflix, or on the podcasts and YouTube communications so omnipresent in contemporary life.
} 


\section{References}

Alfano, C. L., \& O'Brien, A. J. (2016). Envision in depth: Reading, writing, and researching arguments. Pearson.

Broussard, M. S., Soni, J., \& Verminski, A. (2017). Reading, research, and writing: Teaching information literacy with process.

Carillo, E. C. (2018). Teaching readers in post-truth america. Utah State University Press.

Chakrabarti, M., \& Jones, D. (n.d.). Modern love: The podcast [audio podcast]. Retrieved from WBUR.org/ModernLove

Chiseri-Strater, E., \& Kirsch, G. E. (1991). Academic literacies: The public and private discourse of university students. Boynton/Cook Publishers.

Clark, C. L. (2016). Praxis: A brief rhetoric (3rd ed.). Fountainhead Press.

Dictionary, O. E. L. (2019). Infosphere. In Oxford english living dictionary. Retrieved from https://en.oxforddictionaries.com

Edbauer, J. (2005). Unframing models of public distribution: From rhetorical situation to rhetorical ecologies. Rhetoric Society Quarterly, 35(4), 5-24. http://doi.org/10.1080/ 02773940509391320

Flowers, A. (n.d.). Crime junkie [audio podcast]. Retrieved from CrimeJunkiePodcast.com

Gere, A. R. (1994). Kitchen tables and rented rooms: The extracurriculum of composition. College Composition and Communication, 45(1), 75-92.

Hartman, S. (2007). Lose your mother: A journey along the atlantic slave route. Farrar, Straus; Giroux.

Horton, M. (Producer). (n.d.). Status: Immigration \& people [audio podcast]. Retrieved from StatusPodcast.com

LeFevre, K. B. (1986). Invention as a social act. Southern Illinois University Press.

Lowe, L. (2015). The intimacies of four continents. Duke University Press.

Mahar, A. (Producer). (n.d.). Broken english [audio podcast]. Retrieved from BrokenEnglishPodcast.com

McComiskey, B. (2017). Post-truth rhetoric and composition. Utah State University Press.

McKesson, D., \& Kramer, J.C. (Producers). (n.d.). Pod save the people [audio podcast]. Retrieved from https://crooked.com/podcast-series/pod-save-the-people/

Oberlies, M. K., \& Mattson, J. L. (2018). Framing information literacy: Teaching grounded 
in theory, pedagogy, and practice. Association of College \& Research Libraries.

Online, O. (n.d.). Post-truth, adj. In OED online. Oxford University Press. Retrieved from http://www.oed.com/view/Entry/58609044

Peters, M. A. (2017). Education in a post-truth world. Educational Philosophy and Theory, 49(6), 563-566. http://doi.org/10.1080/00131857.2016.1264114

Richardson, E. B. (2003). African american literacies. Routledge.

Robinson, P., \& Willians, J. (n.d.). 2 dope queens [audio podcast]. Retrieved from WNYCStudios.org/Shows/DopeQueens

Roozen, K. (2008). Journalism, poetry, stand-up comedy, and academic literacy: Mapping the interplay of curricular and extracurricular literate activities. Journal of Basic Writing, 27(1), 5-34.

Shelf, T. R. (2018). Alternative facts, post-truth and the information war. Grey House Publishing.

Smallwood, S. E. (2007). Saltwater slavery. Harvard University Press.

Times, T. N. Y. (n.d.). The daily [audio podcast]. Retrieved from https:// www.nytimes.com/column/the-daily

Young, V. A. (2010). Should writers use they own english? Iowa Journal of Cultural Studies, 12(1), 110-117.

Young, V. A., Barrett, R., Lovejoy, K. B., \& others. (2018). Other people's english: Code-meshing, code-switching, and african american literacy. Parlor Press. 